\title{
Entrevista al profesor François Ost
}

\author{
Germán SANDOVAL* \\ Pauline CAPDEVIELLE**
}

Con ocasión de la colaboración de François Ost $^{1}$ en las actividades de la División de Estudios Jurídicos del CIDE en la Ciudad de México en febrero de 2014, nos reunimos con el destacado profesor de la Universidad de Saint-Louis (Bruselas, Bélgica) para conversar sobre algunos de sus principales temas de investigación y proyectos académicos. Sentados con un café en una librería del parque de Chapultepec, compartimos un diálogo sobre sus perspectivas filosóficas, proyectos de investigación y su trabajo en torno al derecho y la literatura.

Agradecemos ampliamente al profesor Ost por esta enriquecedora charla, a la doctora Leticia Bonifaz Alfonzo por su atenta disposición y colaboración para que se llevara a cabo esta entrevista,

* Profesor en la Facultad de Derecho de la UNAM.

** Coordinadora de la Cátedra Extraordinaria "Benito Juárez" de la UNAM sobre laicidad.

1 François Ost es vicerrector de la Universidad Saint-Louis de Bruselas (Bélgica), donde enseña el derecho y la filosofía del derecho. Además, es docente de la asignatura de Filosofía del Derecho en la Universidad de Génova y profesor invitado en la Universidad de Louvain (Bégica).

Sus principales líneas de investigación giran en torno a las relaciones entre derecho y literatura, el derecho del medio ambiente, la filosofía de los derechos humanos, así como la teoría del lenguaje y de la traducción.

Entre sus obras destacan: Raconter la loi. Aux sources de l'imaginaire juridique, París, Odile Jacob, 2004; Traduire. Défense et illustration du multilinguisme, París, Fayard, 2009; De la pyramide au réseau? Pour une théorie dialectique du droit, Bruxelles, Publications F.U.S.L., 2002 (con M. van de Kerchove). 
así como al doctor Juan Vega, director de la Revista Problema por su interés y diligencia en la publicación de la misma.

\section{1. ¿Cómo podría definir su obra: filosófica, científica o sociológica?}

Sin duda es una pregunta difícil de contestar, pues todo mi trabajo, como también el de Michel van de Kerchove, y de manera general el de la escuela de Bruselas en las facultades de Saint Louis, se ha desarrollado bajo el estandarte de la interdisciplinariedad, de la cual seguimos haciendo la teoría, pues es una disciplina difícil.

En un principio, queremos ser buenos juristas que conocen el derecho desde adentro para poder dialogar de manera consciente con los colegas, autores de doctrinas y los operadores jurídicos. Pero esta perspectiva siempre nos ha parecido demasiado estrecha. Lo que quisimos hacer, entonces, fue sumergir la comprensión y la práctica del derecho en una visión más global del humano en la sociedad, por lo que debo reconocer al respecto que mi perfil de filósofo es el que ha sido más relevante y decisivo en mi trabajo. Sin llegar a chauvinismos ni a una jerarquía entre disciplinas, pienso que la filosofía, que no tiene objeto en sí, sino que enseña a pensar, a hablar y a actuar, es una magnífica llave para arbitrar entre los diferentes puntos de vista de las ciencias. Por lo tanto, el trabajo multidisciplinario está en sí mismo fundado sobre una línea filosófica esencialmente epistemológica, es decir, una reflexión permanente sobre lo que es pensar y actuar. Y porque el derecho tiene una vocación normativa, la filosofía puesta en práctica es también una ética, una meta-ética, que nos enseña sobre las condiciones de posibilidad del actuar ético. A lo largo de estas diferentes investigaciones, incursioné en la historia, en la sociología, y también en la sicología. De hecho, voy a arriesgar una hipótesis: con el paso de los años, me pregunto si las diferencias entre las disciplinas que tanto nos ocupan, son finalmente tan importantes. Pienso, más bien, que son las diferencias entre los paradigmas que son importantes. Si compartimos un mismo paradigma - por ejemplo, un paradigma hermenéutico más que uno empiricista-, la multidisciplinariedad resulta muy fructífera. Uno será sociólogo, otro jurista, otro más sicólogo, pero tendremos la 
sensación de colaborar juntos a la elucidación de una pregunta a partir de una misma intuición y de un mismo paradigma. En cambio, entre paradigmas diferentes dentro de una misma disciplina, las guerras son terribles y las fronteras reales. No hay que intentar a cualquier precio conciliar el agua y el fuego. Es una idea nueva para mí, pero la encuentro bastante movilizadora. Es la idea de que podemos colaborar entre disciplinas diferentes, a partir del momento en que compartimos el mismo paradigma.

2. Existen influencias de Bachelard y Kuhn en su obra, ¿qué hay detrás de estas nociones de paradigmas?, ¿hay una validación filosófica, histórica, social, unidimensional?, ¿existen para usted saberes relativos?

Thomas Kuhn tiene una concepción muy amplia del paradigma; no es solamente un método, una hoja de ruta o una agenda de preguntas. Para él, un paradigma pueden ser cosas diferentes: en primer lugar, son las leyes fundamentales que están en la base de la teoría; después, son valores; también, es una visión del mundo (Weltanschauung), metafísicas, y, finalmente, lo más divertido o sencillo, imágenes. Vamos a decirlo así: los paradigmas son metáforas e imágenes que remiten a una visión del mundo basada en valores, y traducidos en reglas fundamentales. Por lo mismo, un paradigma es más que una cuestión de método científico, es verdaderamente una visión del mundo. Sin quererlo, en la mayoría de mis trabajos he llegado a un ejercicio dialéctico. Como visión del mundo, como valor, como paradigma hermenéutico y dialéctico. En realidad no veo noción más fundamental que pueda usar el investigador.

3. Ahora bien, uno de sus enfoques de trabajo ha sido la relación entre derecho y literatura, ¿cómo surge esta inquietud?

Se hizo progresivamente. En mis trabajos sobre derecho natural -en Bélgica existe todavía un curso de derecho natural que sirve más que todo para reflexionar de manera crítica sobre el derechosurgían siempre ejemplos literarios, como por ejemplo Antígona de Sófocles. Poco a poco, me empecé a dar cuenta que la literatura tiene 
muchos ejemplos y respuestas originales sobre cuestiones fundamentales relativas a la justicia, al poder y al derecho. Me percaté rápidamente de que esta corriente existía desde algunas décadas en Estados Unidos y que se habían empezado a realizar algunas traducciones en Europa; así que me lancé con mucho entusiasmo en esta perspectiva, ya que desde el punto de vista filosófico siempre he pensado que la imaginación es una calidad importante para el ejercicio del derecho. La capacidad de ficción, de producción de relatos, es, sin duda, el origen mismo del trabajo de la razón. No hay que oponer razón y emoción, o teoría y arte. Soy de los que piensan, como lo pensaba el mismo Kant, que la intuición, es decir, la capacidad de imaginación, es la fuente de nuestras percepciones científicas, y tal vez de nuestras convicciones morales. Y a partir de ahí, podemos desenrollar el hilo y empezar un recorrido en la literatura, desde la tragedia griega hasta Kafka y otros autores más contemporáneos, pasando por don Quijote y Shakespeare, y finalmente encontrar con frecuencia respuestas originales a las cuestiones más fundamentales de la filosofía del derecho.

4. Desde el punto de vista del derecho y de la literatura, ¿cuál es la relación entre los trabajos de Portalis y la literatura?

Portalis, como lo sabemos, es conocido por ser el autor principal del Código napoleónico de 1804. Era el ministro de la justicia y de los cultos de Napoleón Bonaparte, y fue también el que negoció el concordato que reconcilió Francia con el Vaticano. Portalis era un provenzal y un abogado del Ancien régime que había defendido causas difíciles durante el reinado de Luis XVI, en particular la de los protestantes. Era un hombre valiente, aunque un hombre de orden. Cuando la Revolución francesa lo exilió, Portalis se refugió en la casa de una baronesa en Alemania, y escribió un libro de filosofía del derecho, que sin ser una obra maestra, es bastante interesante. Por mi parte, ya que me lo preguntan, he escrito una obra de teatro, titulada La Nuit la plus longue. Sade et Portalis au pied de l'échafaud. ${ }^{2}$ El punto de partida de

2 N.T.: en español, el título tentativo sería La noche más larga. Sade y Portalis al pie del cadalso. 
esta obra se basa en un pequeño hecho histórico que descubrí por casualidad: estos dos personajes -el marqués de Sade y Portalis-se encontraron juntos, escondidos en una maison de santé - una especie de hospital para enfermos mentales-, administrada por el doctor Coignard, calle Picpuces en París, durante julio de 1794, es decir, en lo más fuerte del Terror y en víspera de la caída de Robespierre. En estas circunstancias difíciles, estos dos hombres buscaron hacerse olvidar en este asilo, en el cual, por lo demás, las condiciones de vida eran bastante agradables. De hecho, tal vez era más un hotel de lujo que un asilo. Me pareció extraordinaria esta casualidad histórica que reunió a Portalis -el hombre del orden y del Vaticano que hace posible la firma el Concordato - y a Sade, que todos conocemos como el hombre de Sodoma y Gomorra. Así que imaginé un diálogo durante una noche entre estos dos hombres en todo punto opuestos, y para poner un poco de suspenso, un salvoconducto que permitiera a sólo uno de ellos escapar. ¿Cuál de los dos se beneficiará del salvoconducto? No les daré la respuesta, pero no es necesariamente la que uno podría pensar. Esta ficción fue la ocasión de dialogar con Sade y Portalis, pero sobre todo de poner en la boca del segundo ciertas críticas hacia Sade. Y también lo contrario, ya que Sade puede denunciar con mucha eficacia la buena conciencia y las contradicciones ideológicas del código burgués —el Código Civil de 1804-, especialmente respecto del status de las mujeres y de los esclavos. Fue muy divertido poner en boca de Sade discursos modernos, que de hecho ha sostenido, que no he inventado, que se referían a la defensa de los más vulnerables. Escribí un libro más docto sobre Sade, pero tuve la sensación de no haber agotado todo lo que tenía que decir, porque con Sade no discutimos sobre el plan intelectual. Sus tesis son tan fuertes que hay que abordarlas desde la imaginación. Y me pareció que el método teatral era el instrumento idóneo para seguir este diálogo con Sade.

5. Si tuviera que describir la filosofía del derecho actual, ¿escogería a Sade o a Shakespeare?

Escogería a Shakespeare, pero no por su moralidad. Ambos me parecen interesantes, ya que ven en el fondo de la condición humana 


\section{GERMÁN SANDOVAL / PAULINE CAPDEVIELLE}

y dicen cosas extremadamente profundas sobre el humano, que a veces son desagradables. Para el derecho global, escogería ciertamente a Shakespeare, puesto que no hay tema que no haya abordado. Víctor Hugo lo llamó "Hombre océano", ya que en las treinta y seis obras que nos dejó, pueden encontrarse todas las situaciones y todos los personajes. Se encuentra cómodo tanto para describir a los reyes y a los obispos, como a las prostitutas y a las huestes, y todos tienen una realidad humana. Su teatro abraza al mundo entero. Ya tengo la respuesta a su pregunta: su teatro tenía el nombre de El Globo, y no conozco tema alguno que no haya sido tratado por Shakespeare: el sueño, el amor, la locura, el deseo, la ciencia, el heráldico, la naturaleza y las tormentas, las islas desiertas... Lo entendió todo, y acompañó el momento en el que la City de Londres se abrió al mundo entero, y que los capitanes y los exploradores regresaban de los mares lejanos. Estaba también en el cruce de las luchas religiosas: su familia era católica, pero se tenía que esconder. Se puede hacer una experiencia muy interesante: creo que no hay muchas ciudades o países en el mundo donde no se interprete unas obras de Shakespeare en este momento. Por supuesto, no sé si hoy mismo se está actuando una de sus obras en México, pero muchas veces se están interpretando en Bruselas dos o tres obras de Shakespeare al mismo tiempo. Por otro lado, se ha podido decir que Sade fue el precursor del hiper-individualismo moderno, de la evaporación del derecho común y de la exacerbación del deseo personal. Incluso existen tesis que muestran el lado perverso de este hiper-individualismo moderno. En este sentido, Sade podría ser una parte de la verdad del mundo contemporáneo. Pero no creo en la universalidad de su modelo. Lo que descubrí al escribir el libro sobre Sade es que al rechazar la ley común - la ley política con sus poderes, sus cárceles, su policía-, no desembocamos en un Estado más suave, más agradable, sino en cambio, sobre una ley mucho más cruel: la ley del perverso. Es la paradoja que subyace al aceptar la idea que la ley común libera, en realidad, de una ley personal más severa y más cruel. Hay dos grandes autores que nos lo muestran: Sade con este modo violento, donde la ley del perverso es una ley cruel para los demás y para sí mismo, y otro autor, Kafka, que no es perverso, pero que también narra la desaparición y la imposibilidad de la ley común. Al en- 
contrarse frente a sí mismo, se vuelve para él un juez de crueldad infinita, consumido por la culpabilidad y la duda. En Kafka hay un verdadero sufrimiento de la ausencia de la ley.

6. Si usted fuera a escribir una obra literaria sobre nuestra época, ¿cómo la llamaría?

Ahora mismo no tengo respuesta, ya sabemos que la inspiración literaria es algo caprichosa. Tengo algunos proyectos en mente, pero la experiencia muestra que de diez proyectos, sólo uno prospera. No se sabe por qué, son las vías imprevisibles de la creación. Tampoco sé si lo podría lograr, soy un científico y de manera muy accesoria un literario. Tal vez, siendo sensible a los fenómenos de las redes de Internet y al mundo, podría escribir sobre una relación amorosa exclusivamente basada en ellas. Aquí hay una pista interesante, me sorprende que no haya sido más explorada. Tendría que ser una especie de Romeo y Julieta a la hora de Twitter o Internet. Pero su pregunta me da mucho que pensar...

7. Regresando ahora a sus trabajos más científicos, ¿existe, detrás de su obra "De la pirámide a la red", una teoría de la ciudadanía?

De hecho, estaría muy interesado en escuchar su opinión, para saber cómo usted lo ha entendido. Pero ya que lo pregunta, podemos decir que este libro quiere también dar su lugar al protagonismo del sujeto de derecho, es decir, al ciudadano. Mi tesis es que cada persona, con sus propios poderes y competencias, puede ser actor de la juridicidad y contribuir a validar, invalidar e interpretar la regla jurídica. Como todos los sociólogos del derecho, soy sensible a la capacidad de iniciativa y acción de los sujetos de derecho para movilizar el derecho en función de sus propias estrategias. Es algo muy importante que señalar: el sujeto de derecho no es solamente el destinatario de reglas penales que prohíben hacer una u otra cosa. El sistema jurídico también es un conjunto de recursos, procedimientos y derechos que pueden ser movilizados por los actores jurídicos para sus propias estrategias, ya sea de manera desinteresada, 
como por ejemplo, el combate a favor de los derechos humanos, ya sea conforme a los intereses patrimoniales y financieros de las grandes corporaciones que utilizan todos los recursos del sistema jurídico para llegar a sus metas. Una segunda respuesta es que la teoría del derecho como red toma en cuenta la pluralidad de las fuentes del derecho, y en particular el de las asociaciones civiles y organizaciones no gubernamentales. Algunas de ellas tienen un bargening power - un poder de negociación-, y un presupuesto que hacen de ellas verdaderos poderes privados y actores ineludibles en el escenario internacional. Pienso, en especial, en asociaciones de defensa del medioambiente o asociaciones humanitarias. En la crisis del Ébola que conocimos hace poco, el actor más eficaz fue, sin duda, Médicos sin Fronteras. La teoría del derecho como red tiene el mérito de tomar en cuenta la acción de algunos actores jurídicos que no disponen, naturalmente, de la misma capacidad de influencia sobre el sistema jurídico, pero que pueden todos, poco o mucho, influir en el desarrollo de dicho sistema.

8. La idea de red parece sugerir la existencia de relaciones más horizontales y recíprocas de creación y aplicación del derecho. Sin embargo, la fuerza del mercado en las relaciones sociales parece crear un desequilibrio, especialmente en los países emergentes. ¿Cómo entender el papel del mercado en el paradigma de la red?

El mercado es evidentemente una red. No hace desaparecer el fenómeno de poder, al contrario, lo esconde bajo la apariencia de la negociación. Este poder es menos visible que en la época de Luis XIV, cuando el soberano afirmaba "yo soy el Estado" y se rodeaba de todo tipo de rituales. Es por eso que en nuestro libro nunca decimos que la red ha reemplazado la pirámide. El título mismo se presenta como una pregunta: "De la pirámide a la red" con un punto de interrogación. La hipótesis es que vivimos en una especie de punto intermedio y ello vale tanto para las sociedades en construcción o Estados débiles, como también para los viejos Estados de derecho. Por ejemplo, lo vemos actualmente en la negociación entre Estados Unidos y Europa de un trato económico que tendría esta cláusula, según 
la cual los inversionistas privados pueden denunciar las leyes nacionales que comprometen la rentabilidad de los inversionistas. Esta cláusula es terrible, porque significa que los inversionistas privados pueden exigir la desaparición o pedir indemnizaciones respecto de una ley votada por un parlamento nacional, en defensa del medioambiente, por ejemplo. Es un reto mayor y sería muy inocente creer que la red fuera sinónimo de igualdad, transparencia y no explotación. Nosotros los juristas guardamos siempre en la mente la hipótesis del conflicto como dato permanente de la naturaleza humana, la explotación como una coordenada permanente del vínculo social. Y justamente, el derecho verdaderamente aplicado, el derecho que queremos, ha de entenderse como una técnica para valorar y abordar explícitamente el conflicto. Finalmente, como el médico siempre parte de la hipótesis de la fragilidad de la salud, no podemos ser inocentes, y debemos partir de la hipótesis de la fragilidad de la igualdad.

Ciudad de México, 7 de noviembre de 2014. 